\title{
Native Settlements in Makkah Al-Mukarramah Area and Factors Affecting Its Distribution
}

\author{
Abdullah Barrak Alharbi \\ Department of Geography and GIS, Faculty of Arts and Humanities, King Abdulaziz University, Jeddah, Saudi Arabia \\ Email: abdullah.b.alharbi@gmail.com
}

Received 5 September 2015; accepted 3 November 2015; published 6 November 2015

Copyright (C) 2015 by author and Scientific Research Publishing Inc.

This work is licensed under the Creative Commons Attribution International License (CC BY). http://creativecommons.org/licenses/by/4.0/

(c) (i) Open Access

\begin{abstract}
Naturally human beings live in settlements, and through the recognition of the distribution pattern of these settlements, the distribution of the population can be identified, which is implemented as an effective factor for seeking balanced development. Therefore, the distribution of population and native settlements with maps are very important issues because they represent the final outcome between the elements of the human and natural environment. The importance of this study merges from the importance of Makkah Al-Mukarramah area among all other areas of the Kingdom of Saudi Arabia in terms of the weight of population (as the last estimates based on the results of the general census of population and housing in 1431/2010 AD): the population is 7,026,805 habitants, spread over eleven provinces in addition to the headquarters in (Makkah Al-Mukarramah); the region's total area is $\mathbf{1 4 0 , 8 1 4}$ square kilometers. It also merges from religious significance for the city of Makkah Al-Mukarramah. The study followed the descriptive and analytical approaches; in addition, it used cartographic representation method, and it had depended on the data and information obtained from the Department of Statistics publications, and other government authorities, and data and maps from published research related to the subject of the study. The results of the study revealed the geographical distribution pattern of both native settlements and population of each province via the natural and human factors affecting facilitating the knowledge of the huge disparity of the distribution which gave light for recommendations built at the end the study.
\end{abstract}

\section{Keywords}

Native, Settlement, Population, Distribution

\section{Introduction}

Many factors affect the distribution of population: natural factors which consist of climate, water and soil quality; 
human factors such as the demographic factor-population (Mohsen, 2012), like sorts of craft, transports, communications, agriculture, industry, political problems and wars etc. Also population distribution can be affected by the interaction between human and natural elements. Natural factors vary in affecting population distribution from one place to another. Some human factors enabled man to change or re-organized their natural environment conditions by adjusting the local environment to suit human existence. Therefore, no single natural factor has influence act to be considered as a responsible factor for the distribution patterns, without interference of other human factors. Both human and natural factors integrate and overlap with each other to design the spread of population on certain parcel of the earth. The climate, for example, has a significant impact on the population distribution because of its impact on soil and vegetation cover. Also historical factor can be added as a factor affecting population distribution, so the older settlements form human stability and often represent higher population density (Subhi, 1995), as well as other factors such as temperature, one of the most influential elements in the distribution of population in rural areas particularly because it indicates the actual value of rainfall through evaporation and evapo-transpiration processes, thus reflecting its impact on soil and vegetation life cycle (Arichi, 2001). This is demonstrated by the high annual temperature range as a phenomenon reflecting on all provinces of the Makkah Al Mukkaramah area. There are some relative differences that appear in some provinces' climate, but the overall rise in annual temperature and longer summer season, while water resource remains as one of the most vital natural factors influencing population distribution and existence of their settlements (in both rural and urban areas) due to its role in the life continuity (Al-Rayhani \& Al-Samoraay, 1990), the most important human factors affecting the distribution the historical and religious background factors of the city of Makkah Al-Mukarramah itsself, which embraces the holly Mosque and Ka'abah Al-Musharafah attracting human gatherings every religious occasion, industry added as human pull factor affecting distribution of the settlements structure, especially in attracting rural population into big cities (Al-Shomaa', 1980), and transportation as a human factor affecting population and settlements distribution with the extension of transmission lines in a wide network of land transport routes, including the main roads connecting among provinces and cites, and mostly secondary paved roads linking villages and manors. The important factors (human or natural) influencing settlements' distribution for each province will be cited later (see Figure 1).

\section{Literature Review}

The researcher found — as far as he knew — only three studies relevant to the area of this study:

Mohsen Saad Abdul Razak study1988, a geographical analysis of the characteristics of the distribution of the population of settlement in the province of Najaf between urban and rural areas, where the study addressed the characteristics of the population and development as a result of natural variation and spatial movement. The study dealt with the geographical location and its impact on population size, the study examined natural and human factors that actually effect the distribution of the population contrast in the province (Mohsen, 2012).

Noman Mohammed Siam study, rural and urban settlements in Syria, 1987, the study confirmed that the distribution of population and settlements with accompanying maps are considered one of the most important geographical topics because they represent a mirror that reflects all the natural and human elements, combined and interactive, as a final outcome of the interaction between the natural elements of the environment and the human factors (Siam, 1987).

Mohammad Shiban Arichi, The Urban Fringe and the prime factors Affecting its growth: an applied study on Assir Region. The study focus to highlight the impact of development services on the growth of urban fringe, as well as determining the contrast between the urban centers of the vulnerability of being affected by these services (Arichi, 2001).

\subsection{Distribution of Settlements in the Study Area}

The total population of Makkah area is 7,471,975 habitants, according to preliminary results of the population census in 1431 (2010) (Planning, 2010) residing in 1606 settlements (see Table 1) includes towns and villages and manors of different sizes of population, twelve of these towns are provincial capitals, The provinces have varied in rates of number of settlements significantly, Qunfidah province has ranked first by a share of (41.9\%) of the total settlements in Makkah Al-Mukarramah area, followed by Taif province by a share of (33.9\%), and the sum of their shares is just over three-quarters of the total settlements in the area (75.8\%) while the rest of the 


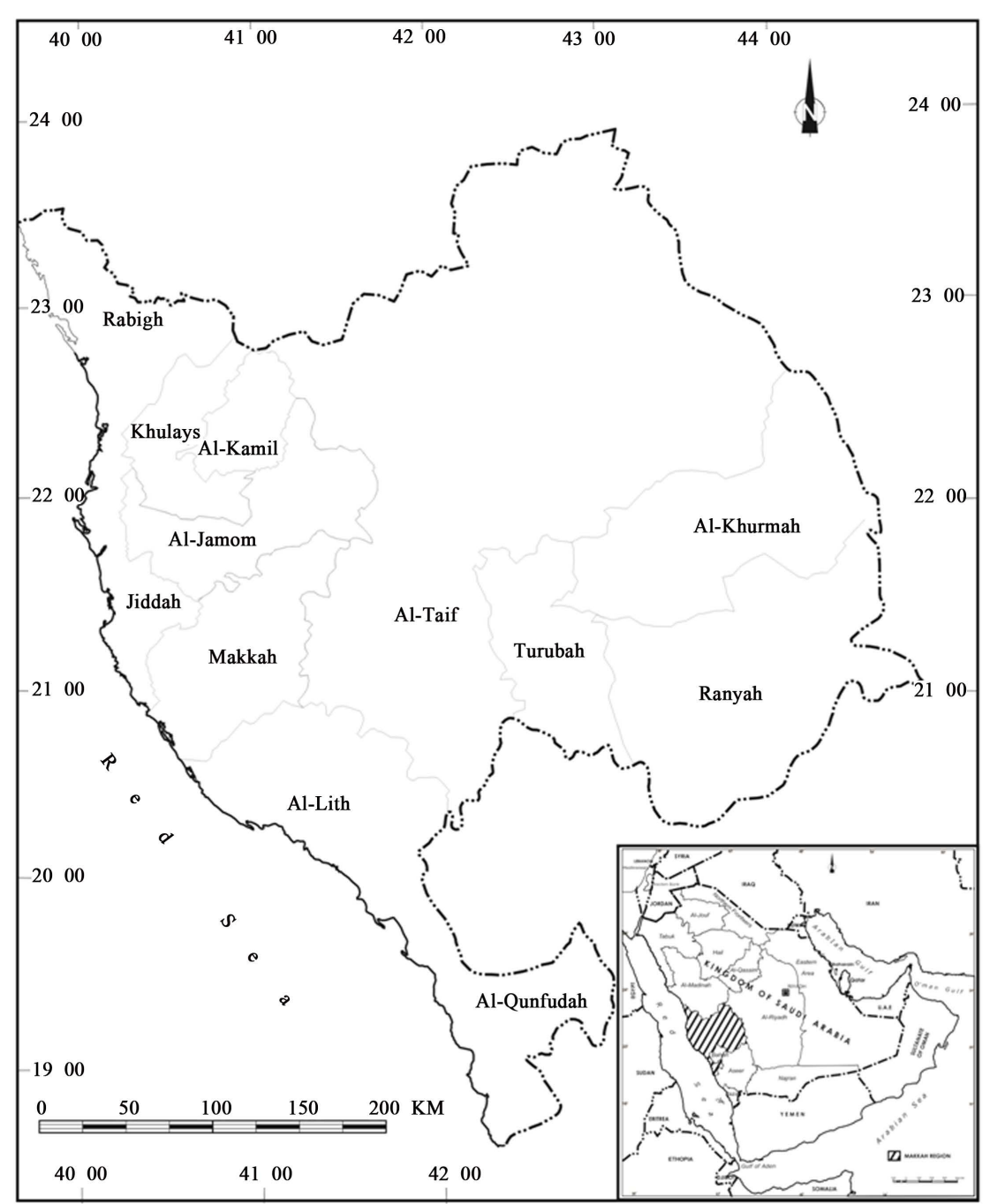

Figure 1. Location of the study area. Source: Atlas of the Department of Statistics and Information, 2004.

Table 1. Distribution percentage of native settlements in Makkah Al-Mukarrmah area.

\begin{tabular}{|c|c|c|c|c|c|}
\hline \multirow{2}{*}{ Serial } & \multirow{2}{*}{ Province } & \multicolumn{4}{|c|}{ Native settlements } \\
\hline & & No. of villages & No. of centers & Total & $\%$ \\
\hline 1 & Qonfidah & 662 & 11 & 673 & 41.9 \\
\hline 2 & Al-Taif & 516 & 29 & 545 & 33.9 \\
\hline 3 & Al-Lith & 87 & 13 & 100 & 6.2 \\
\hline 4 & Al-Jamum & 30 & 2 & 32 & 2 \\
\hline 5 & Makkah & 57 & 10 & 67 & 4.1 \\
\hline 6 & Khulays & 41 & - & 41 & 2.5 \\
\hline 7 & Ranyah & 30 & 7 & 37 & 2.3 \\
\hline 8 & Rabigh & 68 & 3 & 71 & 4.4 \\
\hline 9 & Al-Kamil & 25 & 4 & 29 & 1.8 \\
\hline 10 & Turubah & 31 & - & 31 & 1.9 \\
\hline 11 & Al-Khurmah & 14 & 3 & 17 & 1 \\
\hline \multirow[t]{2}{*}{12} & Jeddah & 662 & 6 & 6 & 0.4 \\
\hline & & 1518 & 88 & 1606 & 100 \\
\hline
\end{tabular}

Source: designed by the author after www.cdsi.gov.sa (Planning, 2010). 
ten provinces shares is less than one quarter of the settlements $(24.2 \%)$, and a clear disparity of distribution is recognized, so the shares of these province is as follows; (Al-Lith) obtained (6.2\%) occupying the third rank, followed by Rabigh province with (4.4\%), then Makkah province by $4.1 \%)$, Khulays province by $(2.5 \%)$, then come the provinces of Ranyah, Al-Jamum, Turubah, and Al-Kamil by $(2.3 \%),(2 \%)(1.9 \%),(1.8 \%)$, respectively, while Khurmah province did not exceed $(1 \%)$ of the total settlements in the area, and Jeddah comes as a last province by $(0.4 \%)$ of the total settlements in the study area (see Figure 2 and Figure 3).

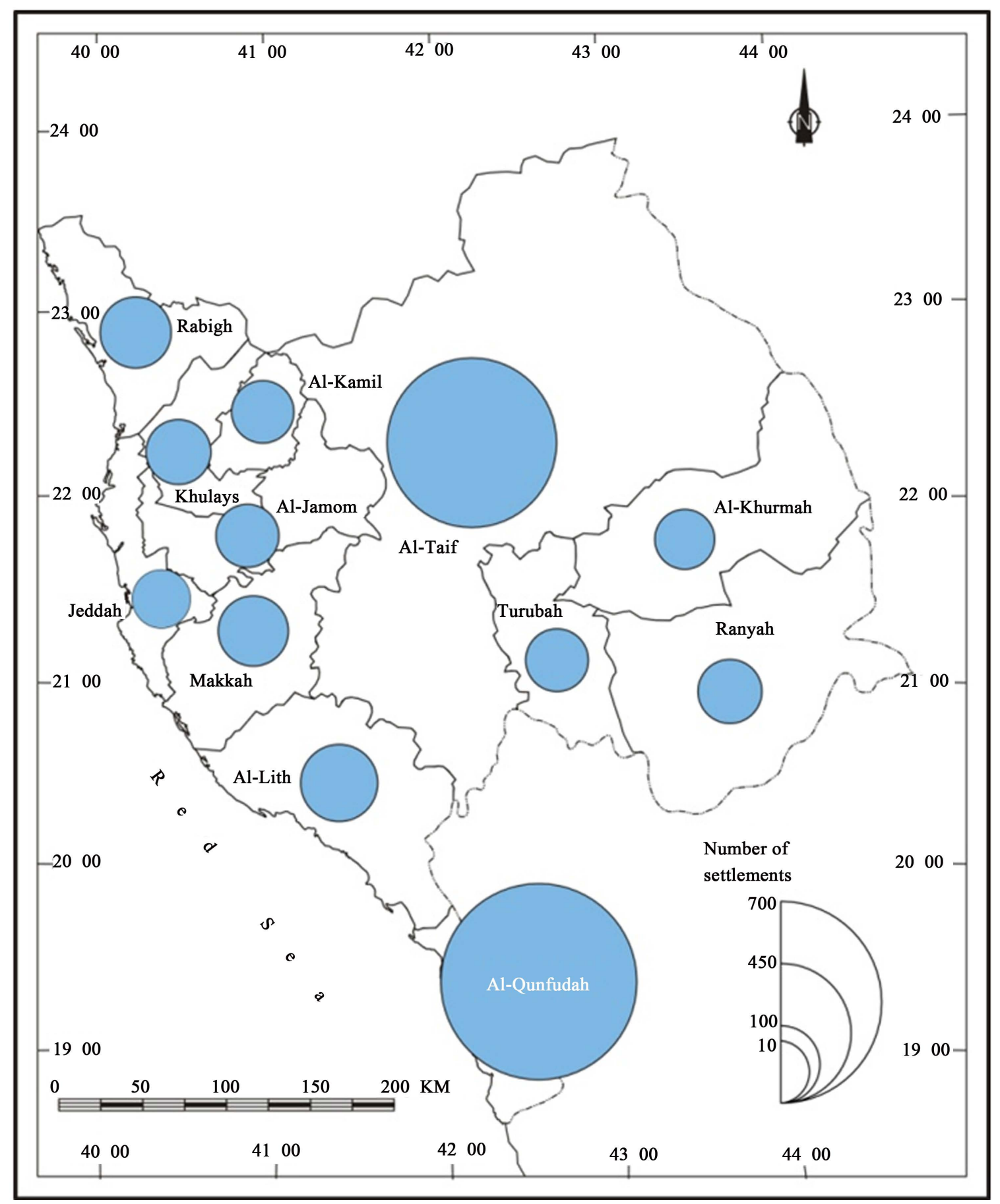

Figure 2. Geographic distribution of native settlements in Makkah Al-Mukarrmah area as provinces wise. Source: Atlas of Department of Statistics and Information (Planning, 2004). 


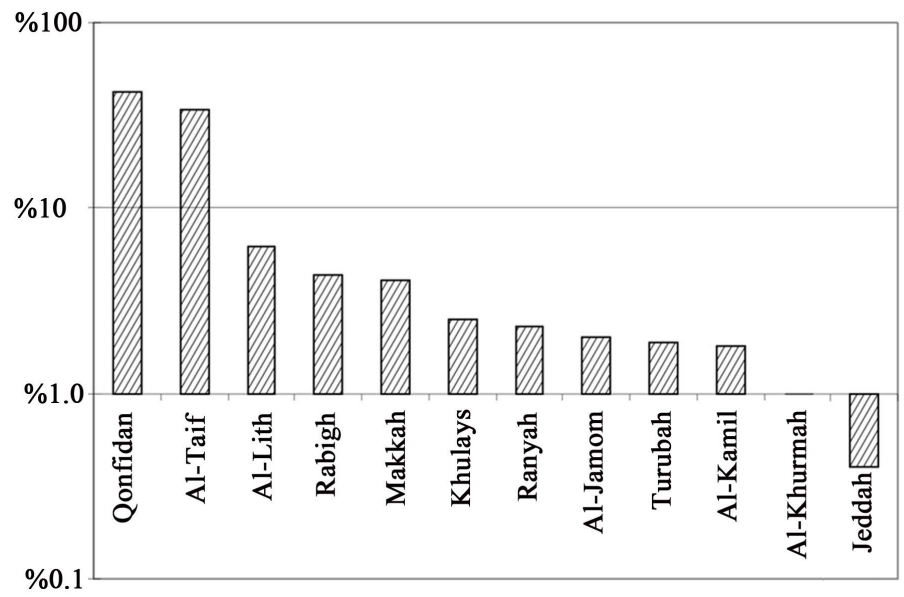

Figure 3. Proportional distribution native settlements by provinces in Makkah area. Source: designed by the researcher based on data from Table 1 .

\subsection{Compatibility between Native Settlements with Their Population Ratios in the Provinces of Makkah Al-Mukarramah Area}

The province of Jeddah, obtained the last rank ( $0.4 \%$ ) in term of native settlements (only 6), while it ranked as the first province in term of population $(3,750,941$ inhabitants) which means it consists more than half of the total population of the area (50.2\%). Taif province occupied Second place in terms of native settlements (545) by (23.9\%), but also obtained the third rank in terms of population $(1,057,016$ inhabitants), which addressed here that there is a relative equivalence between the native settlements and population. Qunfidah province occupied the first place in terms of Number of native settlements(673) with percentage of $(41.9 \%)$, while it occupied the fourth place in terms of population, Al-Lith ranked as the third province in term of native settlements (100) forming a (6.2\%), while it ranked as the fifth province in term of population (137,059 inhabitants), Rabigh province was ranked as the fourth in terms of native settlements, while it obtained the sixth place in term of population (99,183 inhabitants), Makkah province has occupied the fifth rank of native settlements, while it ranked as the second province in terms of number of Population $(1,813,926$ inhabitants). Khulays province had occupied the sixth place in terms of the number of native settlements and obtained the eighth place in population. Ranyah province was ranked as seventh and ranked at ninth place in terms of population. Al-Jamum and Turubah provinces coincided relatively, where Al-Jamum province Ranked as eighth in the number of native settlements, and at seventh place in terms of population, while Turubah province was ranked as ninth in terms of native settlements and ranked as tenth in term of population, Al-kamil province ranked as the tenth in terms of of native settlements but it ranked as twelfth in population, while Al-Khurmah province has coincided completely, so it was ranked as the eleventh in terms of the number of native settlements and also ranked as the eleventh in terms of population, but this coincidence doesn't make any effective sense in the scope of the distribution because of the low value of this coincidence. The above relationships can be refocused again, by dividing the percentage of population over the percentage of native settlements in each province. The output identifies the province average share coresponding each (1\%) of native settlements (see Table 2).

Table 2 illustrates the great inconsistency in the distribution of the population in the provinces of Makkah Al-Mukarramah area, where it is found that provinces of Jeddah, and Makkah, the percentage value of population more than $(125 \%)$ and $(6 \%)$ respectively via only $(1 \%)$ of native settlements in each province. But, in the rest of the provinces, the percentage ratioof native settlements exceeding always the percentage ratio of population. Where the provinces e.g. Al-Jamum, Taif, Khurmah, had reached $(0.7 \%)(0.6 \%)(0.6 \%)$, respectively via (1\%) of native settlements. while the provinces of Turubah, Al-Lith, Khulays, Rabigh, Ranyah, Al-kamil and Qunfidah, declined in population ratio and ranged only between $(0.4 \%)$ in Turubah province, $(0.3 \%)$ in Lith, Khulays, Rabigh, Ranyah, and ( $0.2 \%)$ in Alkamil province and $(0.09 \%)$ in Qunfidah province, which is consider the ultimate lowest proportion through the provinces of the area. And that explains the distribution disparity between the provinces of the study area and the presence of metropolitan (city of Jeddah 3.8 million inhabitants), and Makkah city (1.8 million inhabitants). That resulted in a very limited number of native settlements. While 
Table 2. Shares of each $1 \%$ of native settlements corresponding share ratios of population by provinces.

\begin{tabular}{cccccc}
\hline s & Province & $\begin{array}{c}\text { Pop. corresponds to 1\% } \\
\text { of native settlements }\end{array}$ & s & Province & $\begin{array}{c}\text { Pop. corresponds to } 1 \% \\
\text { of native settlements }\end{array}$ \\
\hline 1 & Jeddah & $125 \%$ & 7 & Rabigh & $0.3 \%$ \\
2 & Makkah & $6 \%$ & 8 & Ranyah & $0.3 \%$ \\
3 & Al-Taif & $0.06 \%$ & 9 & Al-Jamum & $0.7 \%$ \\
4 & Qunfidah & $0.09 \%$ & 10 & Turubah & $0.4 \%$ \\
5 & Al-Lith & $0.3 \%$ & 11 & Al-Kamil & $0.2 \%$ \\
6 & Khulays & $0.3 \%$ & 12 & Al-Khurmah & $0.6 \%$ \\
\hline
\end{tabular}

Source: designed by the researcher depending on the study data.

the rest of the provinces that the proportion of the population to decrease inversely via the ratio of the number native settlements (see Table 2).

\section{Results}

1) Whenever the distribution of native settlements consistent and balanced whole or in part (the percentage of the population of the capital of the province don't exceed more than $18 \%$ of the total population, and indicates richness of resources in the province (Qunfidah and Lith as an example), also the balanced spread of native settlements helped by existing of roads with its different sorts in the these provinces.

2) The unbalanced spread distribution of native settlements in some provinces can be as a result of weakness of resources or to the rugged patch reliefs in some provinces (Makkah, Al-Jamum, Al-Kamil), and the population of the provinces capitals accounted respectively $(97.6 \%, 81 \%$ and $55 \%)$ of the total population of the province.

3) There is a great disparity between the size and level of cities, where the population size of the first major city (Jeddah) population (3.7 million inhabitants) is equivalent to more than double size of the second city Mecca (1.7 million people).

4) In Makkah province, the size of the prime city (Makkah) — equivalent to about 176 times the size of the second city in the same province.

5) The clustered distribution of cities and villages in the Red Sea southern provinces (Makkah, Laith, Qunfidah) where the concentration of most of the cities on the coastal regional road (Jeddah-jazan).

6) Most of the other provinces capitals are located on the main roads (Jeddah-Al-Taif-Riyadhroad) and round about Haramain road (Makkah Al-Makrramah-Medinah Al-Munawwarah Highway).

7) The historical factors played an effective role where semi-metropolitan grew up in Makkah area as a result of this factor, such as Makkah city, but also religious factors remained particularly considerable, as this cityst and as holiest city of Muslimsall over the world conjoined Al-Ka'aba Al-Musharrafah and the Holy Mosque.

The city of Jeddah, in addition to the historic factors, has continued to grow up as a metropolitan due to its geographical location as a backer for Makkah Al-Makrramah city and represents the gate for Pilgrimage and Omrah seasons, and is also considered as the first economic city in Saudi Arabia, conjoining the largest commercial seaport (Jeddah Islamic Seaport), as well as the presence of King Abdul Aziz International Airport linking all countries over the world.

The third city in Makkah Al-Makrramah area is Al-Taifcity, one of the historic cities which becomes in this era Saudi Summer Capital of the country, depending on its natural factors due to its height and location (1700 meters above sea level), which leads the city to be considered as a tourist center at local and regional levels.

\section{Recommendations}

1) The variation of distribution of native settlements and population in the provinces of Makkah Al-Makrramah area resulted in the lack of natural resources especially water resource and vegetation cover, so in the light of this fact the authorities were called to look for activation of water harvesting mechanism projects from flooding valleys, and take advantage permanently of the strategic storage of water. In this way this factor will contribute 
to unequal distribution of native settlements and population.

2) Unbalanced development and concentration in certain areas (major cities) caused the phenomenon of ruralization of cities, where migration towards these major cities affected them significantly, and the cities began to suffer from population pressure, affecting infrastructure. The concerned authorities are called to accelerate the expansion of the establishment of branches of universities and colleges, and affiliated institutions in the capitals of the provinces and towns of the region, influencing satiability of the population of those areas and creating job opportunities.

\section{Acknowledgements}

The researcher thanks the Deanship of Scientific Research, King Abdul Aziz University, Jeddah, for the scientific and financial support for this research project.

\section{References}

Al-Rayhani, Q., \& Al-Samoraay. (1990). Geography of Arid Lands. Bagdad: University of Bagdad.

Al-Shomaa', S. A.-K. (1980). Agricultural Areas in Iraq. Al Najaf: Ministry of Agricultural.

Arichi, M. S. (2001). The Factors Affect the Urban Fringe in Assir Area and Effects of Services in the Fringe Contrast. Jeddah: King Abdulaziz University.

Mohsen, A. S. (2012). Geographic Analysis of Population Alnajaf Province Rural and Urban Settlements. Journal of Education, 5 .

Planning, M. O. (2004). Results of Census, $1425 H$ (2004). Riyadh: Government Report.

Planning, M. O. (2010). Preliminary Results of Census, 1431H. Riyadh: Government Report.

Siam, N. M. M. (1987). Distribution of Settlements in Syria. Riyadh: Imam Muhammad Ibn Saud Islamic University.

Subhi, A. H. M. (1995). Population Distribution. Bairout: Dar Alhuda publishing Inc. 